\title{
Factors Impacting Treatment Choice in the First-Line Treatment of Colorectal Cancer
}

Lourens T. Bloem • Richard De Abreu Lourenço • Melvin Chin •

Brett Ly · Marion Haas

Received: March 4, 2016/ Published online: May 11, 2016

(C) The Author(s) 2016. This article is published with open access at Springerlink.com

\begin{abstract}
Introduction: To investigate the factors that affect the choice of 5-fluorouracil (5-FU) or its oral alternative, capecitabine, as first-line treatment in patients with colorectal cancer (CRC).
\end{abstract}

Methods: Patients treated with 5-FU or capecitabine for CRC between January 1, 2011 and December 31, 2013 in a teaching hospital

Enhanced content To view enhanced content for this article go to www.medengine.com/Redeem/ 05C4F060100E857A.

Electronic supplementary material The online version of this article (doi:10.1007/s40487-016-0020-4) contains supplementary material, which is available to authorized users.

L. T. Bloem

Utrecht Institute for Pharmaceutical Sciences

(UIPS), Utrecht University, Universiteitsweg 99,

3584 CG Utrecht, The Netherlands

R. De Abreu Lourenço $(\bowtie) \cdot$ M. Haas

Centre for Health Economics Research and Evaluation, University of Technology Sydney, Block D, Building 5, 1 Quay St, Haymarket, NSW 2007, Australia

e-mail: Richard.DeAbreuLourenco@chere.uts.edu.au

M. Chin · B. Ly

Nelune Comprehensive Cancer Centre,

Prince of Wales Hospital, High St, Randwick,

NSW 2031, Australia in the Sydney metropolitan area, Australia were identified using the hospital's database MOSAIQ ${ }^{\circledR}$. The electronic medical record of each patient was manually reviewed to extract factors potentially affecting treatment choice. Logistic regression was used to assess which patient and/or treatment factors could explain the choice between 5-FU or capecitabine. Where it was available in the medical correspondence, the explicit reason for the choice made was extracted.

Results: 170 CRC patients were included; 119 on 5-FU, and 51 on capecitabine. The odds of receiving capecitabine as a first-line treatment were positively associated with giving patients a choice in the decision $(\mathrm{OR}=17.51,95 \% \mathrm{CI}$ : 5.37-57.08). Qualitative data suggest treatment choices were motivated by convenience (oral administration) and tolerability. Time from diagnosis to treatment commencement $(\mathrm{OR}=1.02$ per month, 95\% CI 1.00-1.04) was also found to be positively associated with the choice of capecitabine. The odds of being treated with capecitabine were lower for patients who lived further from the treating hospital $(\mathrm{OR}=0.22$, 95\% CI 0.05-0.94). 
Conclusion: This study suggests that patient choice, favoring oral capecitabine over i.v. 5-FU, was a key factor influencing first-line treatment for CRC in this cohort. To respect their autonomy, patients should be involved in the clinical decision making process.

Keywords: Colorectal cancer; Mode of administration; Patient involvement; Treatment choice

\section{INTRODUCTION}

Colorectal cancer (CRC) remains one of the most common cancers worldwide. With an estimated incidence of almost 1.4 million new diagnoses, it represented $9.7 \%$ of all new cancer diagnoses excluding non-melanoma skin cancer. Worldwide, mortality has been estimated to be nearly 694,000 [1]. To treat CRC, a broad range of drugs is now available including fluorouracil (5-FU) alone or with leucovorin (LV), capecitabine, oxaliplatin, irinotecan and targeted agents. Fluoropyrimidines, 5-FU (intravenously administered) and capecitabine (tablet formulated prodrug of 5-FU), are generally used as the backbone of treatment modalities, either alone or in combination with other agents [2, 3]. Numerous studies have compared the efficacy and safety of 5-FU and capecitabine, alone or in combination therapy. Capecitabine, and the combination of capecitabine and oxaliplatin (XELOX or CAPOX) have been shown to be non-inferior to either 5-FU/LV or the combination of 5-FU/ LV and oxaliplatin (FOLFOX or FLOX) [2, 4].

However, the decision to use one or the other of these drugs has implications for both the patient and treating institution; most notably, for health care resource use due to the difference in the mode of administration. While intravenous (i.v.) treatment with 5-FU typically requires the use of indwelling catheters, pumps for continuous infusion and several hospital visits by the patient or home visits by medical personnel, capecitabine is self-administered orally. Thus, the use of 5-FU would be expected to result in increased health care service utilization associated with treatment administration compared with capecitabine [5-12], as well as the costs to the patient for traveling to, and remaining at the hospital for treatment [6, 10, 11, 13]. Given these differences in the mode of administration and potential accessibility of treatment, several studies have noted a preference by patients for capecitabine over 5-FU on the basis of convenience $[14,15]$.

Studies specifically evaluating patient preferences for oral versus i.v. chemotherapy (mostly for CRC) generally show a preference for oral treatment [14-19]. Before and after treatment, the main drivers of preference for oral chemotherapy were convenience of home administration [14-18], the avoidance of i.v. line problems [16, 18], fewer adverse events (AEs) $[17,18]$ and oral administration $[14,15$, 17]. Interestingly, Twelves et al. [14] found fewer occurrences of AEs to be a driver of preference for 5-FU. Other studies have shown that home-based chemotherapy treatments were preferred by the patients $[20,21]$ and led to significant [21] or greater treatment satisfaction [22]. The reasons associated with this preference were convenience, traveling less, lower anxiety, not having to trouble carers and family, having a greater ability to perform other tasks and having a relative close-by $[20,21]$.

The aim of this study was to identify the factors associated with the choice between 5-FU and capecitabine in the first-line treatment of patients with CRC using data from the 
electronic medical records of an Australian metropolitan public hospital. Previous studies have identified factors such as patient age, comorbidities, gender, race, median income, marital status, type of insurance, area of residence, and cancer specific characteristics such as CRC stage, cancer site, prior cancer events, and year of diagnosis as influencing prescribing decisions [23-31]. We sought to consider these factors against the role of patient choice and their actual involvement in treatment decision making where documented. A secondary aim was to specifically identify patients' underlying reasons for their treatment choice where this information was available.

\section{METHODS}

\section{Setting and Study Population}

This was a retrospective, single center study conducted at a teaching hospital in the Sydney metropolitan area. The records of CRC patients who received active treatment via that hospital with 5-FU or capecitabine between January 1, 2011 and December 31, 2013 were included. Eligible patients were identified using a proprietary database, MOSAIQ, the primary electronic database used for outpatient oncology records at the hospital since 2011. If a diagnosis or treatment was unclear, a medical oncologist (MC) and a pharmacist (BL) were consulted to decide whether or not to include that patient in the analysis. For all included patients the choice of first-line treatment, i.v. 5 -FU or oral capecitabine was assessed. Patients who started first-line treatment before January 1, 2011 but were treated during the study period were included in the analysis.

\section{Potential Factors Affecting Treatment}

\section{Choice}

Potential factors affecting the decision to use either 5-FU or capecitabine as the first-line treatment were identified by a comprehensive literature review [14-31] and supplemented by additional factors hypothesized to also impact on the treatment decision. In addition to patient preference as described above, patient demographics and clinical characteristics may also influence treatment choice. Patient and disease characteristics shown to be associated with chemotherapy treatment choice explored in this study were: age, comorbidity, sex, ethnicity (proxied by birthplace), income, marital status, type of insurance, geographic region, CRC stage, cancer site, prior cancer events, and year of diagnosis [23-31]. Additional factors included in this study were number of children, religious affiliation, time from diagnosis to treatment commencement, initial attending physician, involvement of radiation oncologist and prescribing medical oncologist. These factors were included given their availability and speculation of their potential influence on treatment choice. In Australia, 5-FU and capecitabine are subsidized by the Pharmaceutical Benefits Scheme for treatment of CRC resulting in no real financial cost differences for patients. Drug acquisition costs were therefore excluded as a factor influencing choice.

Data were manually extracted from the standard demographic, medical and prescription records within the MOSAIQ database. Where additional information was required that was not contained in MOSAIQ, patient-specific medical oncology correspondence was reviewed. 
For all patients this included searching for information on a number of variables (number of children, comorbidities, stage of CRC at treatment commencement, treatment decision and prescribing medical oncologist) and for qualitative information on the underlying reasons regarding treatment preference from medical correspondence. This included correspondence between medical practitioners and entries in patient medical notes, not specifically addressed to a third party. For some patients, data had to be extracted from older databases used before MOSAIQ. Data not available in any database including the medical correspondence were recorded as "not reported". All data were extracted on site by one author (LB). To verify the validity of the extraction process, a medical oncologist (MC) who had experience using MOSAIQ, double-checked the extracted variables for a sample of patients.

Text extracted from the medical oncology correspondence on the reason for choosing the first-line chemotherapy regimen was initially coded by one researcher (LB). Treatment decisions were categorized into how and by whom they were made (e.g., by the patient, by the physician, or unclear, see Table 1), with supplementary information as to why a decision was made (e.g., convenience, tolerability), extracted based on key-words appearing in the medical record text. Coding decisions were then discussed with another researcher (RL) to ensure consistent classification.

\section{Data Analysis}

Factors affecting the decision to use either 5-FU or capecitabine were analyzed using logistic regression. The treatment decision was the dependent variable, coded as binary between capecitabine and 5-FU. With the exception of
Table 1 Treatment decision categories

\begin{tabular}{ll}
\hline Category & $\begin{array}{l}\text { Medical oncology correspondence } \\
\text { clearly indicated that... }\end{array}$ \\
\hline Physician & $\begin{array}{l}\text {.. the physician had decided which } \\
\text { regimen the patient was going to be } \\
\text { treated with }\end{array}$ \\
One option & $\begin{array}{l}\text {... one option was discussed with the } \\
\text { patiscussed }\end{array}$ \\
Physician & $\begin{array}{l}\text {...a specific treatment regimen was } \\
\text { recommended }\end{array}$ \\
advised/recommended to the patient \\
by the physician, but final choice was \\
left to the patient \\
Patient
\end{tabular}

$N / A$ not applicable

age, time from diagnosis to treatment and distance required to travel to hospital, variables extracted from MOSAIQ and the supporting medical correspondence were coded as categorical.

Initial associations between categorical variables and treatment choice were examined using univariate two-way tabulations and tested for statistical significance using Pearson's Chi-squared test and Cramérs V. For those variables where the tests indicated a possible significant association ( $p$ value $<0.1$ for Chi-squared test, or Cramérs $V>0.2$ ) an odds ratio (OR) was tabulated and tested for homogeneity. All variables which showed either a significantly increased OR, or which 
tested positive for homogeneity were retained for inclusion in the multivariate logistic regression. Despite not demonstrating significance, gender was retained for inclusion as a known demographic of influence, but all the other categorical variables that did not show a significant univariate association were excluded from the multivariate logistic regression.

The subsequent multivariate logistic regression included the categorical variables of significance, gender and the continuous variables of age, time from diagnosis to treatment and distance from the treating institution. The latter variable was subsequently converted to categorical to better capture the distribution of patients and to overcome the impact of extreme data-points on the modeled analysis. Missing data were excluded for all variables. Data analyses were undertaken using Microsoft Excel 2010 and Stata Statistical Software, release 13.

\section{Compliance with Ethics Guidelines}

This article is based on previously treated patients and does not involve any new studies of human or animal subjects performed by any of the authors. Ethics approval for this study was obtained from the South Eastern Sydney Local Health District Human Research Ethics Committee (13/288) and ratified by the University of Technology Sydney Human Research Ethics Committee (2014000002).

\section{RESULTS}

\section{Patient Characteristics}

Review of the MOSAIQ database revealed that a total of 170 CRC patients were eligible for inclusion in this analysis; 119 patients had received initial treatment with 5-FU (14 as single agent), while 51 commenced treatment with a capecitabine-based regimen (22 as single agent). Patient, disease and treatment characteristics are presented in Table 2. 61.8\% of patients were male and the average age at treatment commencement was 63.3 years. 100 patients $(58.8 \%)$ were initially diagnosed with a form of colon cancer, of which more than a third had cancer of the sigmoid colon, while the other 70 patients had rectal cancer. The average time between diagnosis and treatment commencement was 7.63 months, with a very wide range ( $\mathrm{SD}=19.52$ months). The available data indicate that in only 41 (24.1\%) instances was the patient clearly given a choice between starting therapy with either 5-FU or capecitabine. Of the six treating physicians responsible for all 170 patients, one medical oncologist treated almost $70 \%$ of the patients, with two others treating more than $10 \%$ of the patients. A similar distribution of patients was observed for the initial attending physician and the radiation oncologist involved.

\section{Factors Influencing Treatment Choice Variation}

Two-way tabulation of the categorical variables with the dependent variable yielded significant Chi-squared values for "marital status" and "treatment decision" and near significant results for "religious affiliation" and "radiation oncologist". The cut-off for Cramérs V was reached for all four variables. The full results of the two-way tabulations for the categorical variables can be found online. Homogeneity testing and calculation of OR was performed for these four variables. Significantly increased univariate OR were found for "religious affiliation", "marital status" and "treatment 
Table 2 Patient, disease and treatment characteristics of the study population $(N=170)$

\begin{tabular}{|c|c|}
\hline Characteristic & $N(\%)^{a}$ \\
\hline \multicolumn{2}{|l|}{ Patient characteristics } \\
\hline \multicolumn{2}{|l|}{ Gender } \\
\hline Female & $65(38.2 \%)$ \\
\hline Male & $105(61.8 \%)$ \\
\hline $\begin{array}{l}\text { Age at treatment commencement } \\
\text { (years }[\text { st.dev.]) }\end{array}$ & $63.3[13.4]$ \\
\hline \multicolumn{2}{|l|}{ Birthplace } \\
\hline Australia & $72(42.4 \%)$ \\
\hline Elsewhere & $96(56.5 \%)$ \\
\hline Unknown & $2(1.2 \%)$ \\
\hline \multicolumn{2}{|l|}{ Marital status } \\
\hline Married & $85(50.0 \%)$ \\
\hline $\begin{array}{l}\text { Widowed, divorced/separated, } \\
\text { never married }\end{array}$ & $61(35.9 \%)$ \\
\hline Not specified/unknown & $3(1.8 \%)$ \\
\hline Not reported & $21(12.4 \%)$ \\
\hline \multicolumn{2}{|l|}{ Number of children } \\
\hline Yes & $104(61.2 \%)$ \\
\hline No & $18(10.6 \%)$ \\
\hline Not reported & $48(28.2 \%)$ \\
\hline \multicolumn{2}{|l|}{ Religious affiliation } \\
\hline Religious & $88(51.8 \%)$ \\
\hline Not religious & $28(16.5 \%)$ \\
\hline Not specified/unknown/not reported & $54(31.8 \%)$ \\
\hline \multicolumn{2}{|l|}{ Health insurance } \\
\hline Only public health insurance & $110(64.7 \%)$ \\
\hline At least public health insurance ${ }^{b}$ & $14(8.2 \%)$ \\
\hline No private health insurance & $14(8.2 \%)$ \\
\hline Public and private health insurance & $8(4.7 \%)$ \\
\hline Private health insurance & $5(2.9 \%)$ \\
\hline Not known/not otherwise stated & $2(1.2 \%)$ \\
\hline
\end{tabular}

Table 2 continued

\begin{tabular}{ll}
\hline Characteristic & $N(\%)^{\mathbf{a}}$ \\
\hline Not reported & $17(10 \%)$ \\
Comorbidities & \\
None & $44(25.9 \%)$ \\
1 & $43(25.3 \%)$ \\
$2-3$ & $45(26.5 \%)$ \\
$4+$ & $19(11.2 \%)$ \\
Not reported & $19(11.2 \%)$
\end{tabular}

Distance required to travel to hospital

$$
0-5
$$$$
83(48.8 \%)
$$

$52(30.6 \%)$

5-10

$19(11.2 \%)$

$10-40$

$16(9.4 \%)$

$>40$

Average (km [st.dev])

$38.71[114.72]$

\section{Disease and treatment characteristics}

\section{Year of diagnosis}

2000-2009

$27(15.9 \%)$

2010-2011

$77(45.3 \%)$

2012-2013

$66(38.8 \%)$

Diagnosis

C18.0 (caecum)

$19(11.2 \%)$

C18.2 (ascending colon)

$15(8.8 \%)$

C18.3 (hepatic flexure)

$2(1.2 \%)$

C18.4 (transverse colon)

$5(2.9 \%)$

C18.5 (splenic flexure)

$3(1.8 \%)$

C18.6 (descending colon)

$7(4.1 \%)$

C18.7 (sigmoid colon)

$36(21.2 \%)$

C18.8 (overlapping sites of colon)

$0(0.0 \%)$

C18.9 (colon, unspecified)

$1(0.6 \%)$

C19 (rectosigmoid junction)

$12(7.1 \%)$

C20 (rectum) 
Table 2 continued

\begin{tabular}{ll}
\hline Characteristic & $N(\%)^{\mathbf{a}}$ \\
\hline Tumor stage at diagnosis & \\
I & $5(2.9 \%)$ \\
II & $33(19.4 \%)$ \\
III & $72(42.4 \%)$ \\
IV & $58(34.1 \%)$ \\
No tumor & $1(0.6 \%)$ \\
Unknown & $1(0.6 \%)$
\end{tabular}

Tumor stage at treatment commencement

$\begin{array}{ll}\text { I } & 0(0 \%) \\ \text { II } & 29(17.1 \%) \\ \text { III } & 67(39.4 \%) \\ \text { IV } & 74(43.5 \%) \\ \text { Time from diagnosis to treatment } & 7.63[19.52] \\ \text { (months [SD]) } & \\ \text { Treatment decision } & \\ \text { Physician } & 46(27.1 \%) \\ \text { One option discussed } & 37(21.8 \%) \\ \text { Physician recommended } & 18(10.6 \%) \\ \text { Patient } & 41(24.1 \%) \\ \text { Ambiguous } & 17(10.0 \%) \\ \text { Not reported } & 11(6.5 \%)\end{array}$

$S D$ standard deviation

a Numbers represent the number of patients, unless otherwise specified

b Equals 'public' (insurance) in the medical record, while for publicly but non-privately insured this was explicitly noted as 'public, not private'

decision" with significant homogeneity test results for the latter two variables.

The results of the logistic regression are presented in Table 3. Significant results were observed for three variables: patients being given the choice for the treatment decision; time from diagnosis to treatment; and distance from the treating center. First, documentation by the physician that the patient was given a choice of treatment was associated with a higher odds of using capecitabine compared to $5-\mathrm{FU} \quad(\mathrm{OR}=17.51,95 \%$ CI 5.37-57.08). Second, the length of time between diagnosis and commencement of treatment was also significant; the odds of using capecitabine, relative to $5-\mathrm{FU}$, increased the longer was this interval $(\mathrm{OR}=1.02$ per month, 95\% CI 1.00-1.04). Finally, the distance from the patient's home to the hospital was also a predictor of treatment choice; patients living more than $40 \mathrm{~km}$ from the treating center were less likely to be treated with capecitabine $(\mathrm{OR}=0.22, \quad 95 \% \quad$ CI $\quad 0.05-0.94)$. The remaining variables did not statistically significantly influence the odds of commencing treatment with capecitabine when compared with 5-FU.

\section{Reasons for Treatment Preference}

While it was possible to categorize all the patients according to who made the treatment decision, there was little information available on the underlying reasons for this preference. Such information was present in the clinical letters of only 11 patients; of these, two were treated with 5-FU and nine with capecitabine. The underlying reasons, by treatment, are listed in Table 4. Convenience seemed to be the main reason for a preference for capecitabine, associated with its oral mode of administration, and reduced time spent traveling to or visiting the hospital. However, a difference in adverse event profiles also seemed to play a role in a preference for capecitabine. Reasons supporting the choice of 5-FU over capecitabine were stated for two patients: potential adverse events with capecitabine and contraindication to capecitabine. 
Table 3 Logistic regression: factors associated with a treatment decision for capecitabine

\begin{tabular}{|c|c|c|c|c|c|}
\hline Variable & $\begin{array}{l}\text { Capecitabine } \\
(n=48)\end{array}$ & $\begin{array}{l}5-\mathrm{FU} \\
(n=109)\end{array}$ & Odds ratio $^{a}$ & \multicolumn{2}{|c|}{$\begin{array}{l}95 \% \text { confidence } \\
\text { interval }\end{array}$} \\
\hline \multicolumn{6}{|l|}{ Gender } \\
\hline Female & $21(35 \%)$ & $39(65 \%)$ & Ref. & - & - \\
\hline Male & $27(28 \%)$ & $70(72 \%)$ & 1.10 & 0.45 & 2.69 \\
\hline \multicolumn{6}{|l|}{ Age } \\
\hline $\begin{array}{l}\text { Age at treatment commencement } \\
\text { (per year) }\end{array}$ & 66.95 & 62.55 & 1.02 & 0.98 & 1.07 \\
\hline \multicolumn{6}{|l|}{ Marital status } \\
\hline Married & $20(26 \%)$ & $57(74 \%)$ & Ref. & - & - \\
\hline $\begin{array}{l}\text { Widowed, divorced/separated, } \\
\text { never married }\end{array}$ & $19(32 \%)$ & $40(68 \%)$ & 1.67 & 0.62 & 4.45 \\
\hline \multicolumn{6}{|l|}{ Religious affiliation } \\
\hline Religious & $23(28 \%)$ & $59(72 \%)$ & Ref. & - & - \\
\hline Not religious & $5(19 \%)$ & $21(81 \%)$ & 0.42 & 0.10 & 1.77 \\
\hline \multicolumn{6}{|c|}{ Distance required to travel to hospital $(\mathrm{km})$} \\
\hline $0-5$ & $25(33 \%)$ & $50(67 \%)$ & Ref. & - & - \\
\hline $5-10$ & $15(30 \%)$ & $35(70 \%)$ & 0.74 & 0.27 & 2.02 \\
\hline $10-40$ & $6(32 \%)$ & $13(68 \%)$ & 1.47 & 0.39 & 5.47 \\
\hline$>40$ & $2(15 \%)$ & $11(85 \%)$ & 0.22 & 0.05 & 0.94 \\
\hline \multicolumn{6}{|l|}{ Treatment delay } \\
\hline $\begin{array}{l}\text { Time from diagnosis to treatment } \\
\text { (per month) }\end{array}$ & 10.04 & 7.18 & 1.02 & 1.00 & 1.04 \\
\hline \multicolumn{6}{|l|}{ Treatment decision } \\
\hline Physician & $7(15 \%)$ & $39(85 \%)$ & Ref. & - & - \\
\hline One option discussed & $6(16 \%)$ & $31(84 \%)$ & 1.41 & 0.38 & 5.20 \\
\hline Physician recommended & $4(22 \%)$ & $14(78 \%)$ & 1.41 & 0.29 & 6.86 \\
\hline Patient & $27(68 \%)$ & $13(33 \%)$ & 17.51 & 5.37 & 57.08 \\
\hline Ambiguous & $4(25 \%)$ & $12(75 \%)$ & 2.40 & 0.47 & 12.31 \\
\hline
\end{tabular}

a Odds ratios adjusted for all variables in the logistic regression

\section{DISCUSSION}

The results from our study indicate that three variables were significant in explaining the variation in 5-FU and capecitabine use in the first-line treatment of the identified CRC patient cohort: giving the patient a choice of treatment and a longer time between diagnosis and treatment commencement were significantly associated with choosing 
Table 4 Underlying reasons for preference regarding a specific treatment decision

Reasons to choose 5-FU

Treatment decision

category

"Given the potential for hand-foot syndrome with capecitabine,

Patient

it is likely that she will prefer intravenous 5-FU”

“... she had an asymptomatic pulmonary embolus requiring anti-coagulation. (...)

Physician

this precluded her from participating in the trial that would access oral capecitabine”

Reasons to choose capecitabine

Treatment decision

category

"... he preferred not to have a portacath"

Patient

"She is not keen to have intravenous treatment"

Patient

"He was not keen to have infusional chemotherapy in the beginning and his difficulty

Patient

with mobility and discomfort with long waits has further convinced him so”

"... there is ample data to suggest it is equivalent and possibly better tolerated and certainly far less cumbersome for the patient leading to other cost savings in terms of time spent in chemotherapy administration”

“... he is not very keen $(. .$.$) as he does not want to take time off work to allow for the$ 2 days that he will need to attend every fortnight"

"We have advised that he receive oral capecitabine, concurrent with the radiotherapy, as this tends to be better tolerated than intravenous 5-fluorouracil (5-FU)”

"I thought it was reasonable to offer her palliative systemic chemotherapy but, in an attempt to reduce the risk of significant toxicity, I thought it appropriate to start with single agent oral 5-fluorouracil analogue capecitabine”

"In view of the equal efficacy of both the agents the patient would prefer, from a convenience point of view, to have treatment with capecitabine”

"... given the fact that she already has metastasis, she is eligible for the oral version of analogue of 5-fluorouracil capecitabine”

One option discussed

Patient

Physician recommended

Physician

Patient

Physician

capecitabine, while patients living some distance from the hospital were less likely to be treated with capecitabine. The latter seems paradoxical at first, as it might be expected that patients living further from the hospital would prefer, or be offered, oral treatments such as capecitabine to enable them to stay at home whilst on treatment and avoid regular hospital visits. It is possible that patients made a choice to sacrifice time away from home to complete each cycle of treatment in hospital (resulting in an overall shorter time on treatment; $48 \mathrm{~h}$ of treatment on 5-FU or FOLFOX chemotherapy vs 2 weeks on capecitabine or CAPOX), or a perception by the physician of differences in the type of toxicity that might be encountered and the capacity to deal with those toxicities remotely. While toxicity data were not available, the impact of potential comborbidities was tested in univariate analyses and found to not influence choice. In addition, the influence of contraindications on treatment choice was noted where these were specifically stated in patient notes. 
Our results show that the time from diagnosis to commencement of treatment was significantly associated with choosing capecitabine. While it is possible that the increased time interval between diagnosis and commencement of treatment, which was noted to be significant, was a surrogate marker for performance status or increased co-morbidities, it would be speculative to state that this was the case for all patients. Unfortunately ECOG performance was not available for patients in this sample: performance status was not always sequentially recorded in the electronic health record, MOSAIQ. The number of comorbidities was available, but initial univariate testing showed no association between the number of comorbidities and treatment choice so this was excluded from subsequent multivariate analyses.

A caveat to this result is that the records used to inform our analysis did not consistently capture the time of disease recurrence where it occurred, such that the actual interval between newly emergent disease requiring treatment and treatment starting may be shorter than calculated. This could not be clarified further with the available data. Data issues notwithstanding, we found it difficult to explain that the longer a treatment decision appeared to be deferred, the higher was the chance that a patient was treated with a capecitabine-based regimen. We explored the possibility that the timing of public subsidy for capecitabine played a part, given that it was not recommended for funding until November 2008 for metastatic CRC in conjunction with oxaliplatin (CAPOX), sometime after the availability of publicly subsidized 5-FU. A supplementary regression including a dummy variable for the introduction of subsidized capecitabine failed to show significance in this regard. Perhaps it could indicate a more considered and resolute decision by the patient. That is, this variable might be a proxy for expected tolerability effects associated with 5-FU; that is, the further patients are away from their initial diagnosis the less likely they are to accept what might be considered "invasive" treatments and perhaps use capecitabine as a single agent in this category.

The main factor influencing treatment choice was a treatment decision made by the patient compared with one made by the physician. When patients were given a choice, the chances that a treatment decision was made in favor of capecitabine rather than 5-FU were significantly higher. This finding corresponds to previously reported studies of patient preference: provided that efficacy is not compromised, most patients expressed a preference for oral chemotherapy compared to i.v. treatment, mostly due to the convenience of oral administration at home, the avoidance of i.v. line problems and fewer AEs [14-22]. Our review of patients' clinical records revealed similar underlying reasons for patient preferences: the convenience of oral administration, and less travel and waiting time. Care is required when drawing conclusions based on this outcome, as the extracted sections of medical correspondence that described the treatment decision process were highly variable in terms of the amount of text and detail provided and were only available for a small number of patients. Treatment intent was not extracted from the database so it would be speculative to comment on this point beyond what could be extracted from the patient notes. However, active involvement of patients in the treatment decision process is a recommended aspect of patient-centered care as it indicates respect for their autonomy.

Indeed, patient participation in the medical decision making process has been shown to influence patient satisfaction [32]. Women with 
breast cancer who were not given the opportunity to make a choice fared less well psychologically (they expressed a diminished positive attitude) than women who were offered a choice between treatment options. In addition, final decision making by the patient rather than the physician led to greater psychological wellbeing [32]. Other studies have shown that a majority of patients prefer to make either an autonomous or a shared decision (i.e., together with their physician) [16, $33,34]$. In a recent review of patient preferences related to the choice of treatment and mode of decision making, Damm et al. [35] found that the majority of CRC patients expressed a preference for a passive role in the decision making process. This is consistent with our data in which approximately $60 \%$ of decisions were the result of a direct choice by the physician, or indicate some degree of physician direction. Nonetheless, our results suggest that patient involvement in treatment choice is a significant predictor of the use of capecitabine compared with 5-FU. It might be reasonable to expect therefore that if more patients were able to be actively involved in treatment decision making, the use of capecitabine might be higher than we have observed.

There are several limitations to this study. First, it was conducted at one site in Australia, and almost $70 \%$ of patients were treated by one physician. This limits the external applicability of our results, both within the Australian setting and to other jurisdictions where differences in clinical practice or access to chemotherapy might impact on the choice of treatment for CRC. Second, the information extracted from medical correspondence was variable and relied on what had been entered. This varied, in terms of both consistency and detail. As a result, for instance, it was not feasible to determine if a shared decision making approach was actually used, only to dichotomise how decisions were made. Physician attitudes and biases toward one treatment or another have not been fully explored. Finally, our study had a limited number of observations: 170 cases of CRC that were not evenly balanced across the treatment groups were extracted from the relevant database. This, coupled with the existence of a substantial proportion of missing data for a number of variables, reduces the explanatory power of our analysis. With larger study populations, more significant associations might have been discovered, including between the different options of treatment: single agent vs combinations. Two other studies that also examined treatment patterns for capecitabine and 5-FU included 4250 and 636 patients respectively [36, 37]. Both assessed factors associated with treatment choices for single agent as well as combination therapy (CAPOX/ XELOX vs. FOLFOX) as first-line treatment in (metastatic) CRC patients from the USA and Australia. In the study by Satram-Hoang et al. [36], the population who received capecitabine rather than 5-FU was older, and a higher proportion was female, had lower CRC stage at diagnosis but a higher tumor grade, and had higher incomes. Comorbidity score and race were not associated with a specific single agent treatment. CAPOX treatment was associated with a higher overall CRC stage at diagnosis and a trend was observed toward people in this group being older. Comorbidity, sex, race, income and tumor grade were not associated with a specific multi-agent therapy. Compared to those receiving i.v. treatment, more patients receiving capecitabine or CAPOX were living in western USA, and a higher proportion had at least a college degree [36]. Finally, in Australia, patient age at diagnosis was found to be 
significant, with older patients more often receiving single agent capecitabine, as well as primary tumor site, with colon cancer patients more often receiving FOLFOX [37].

Notably, these studies focused only on patient and disease characteristics as determinants of treatment modality and not the source of the treatment decision. It is likely that in making their treatment choice, patients and physicians alike evaluate some of the disease and patient characteristics considered in those larger studies. However, using the information available in patients' charts, we were able to identify that convenience is an additional underlying reason which influences preferences.

\section{CONCLUSION}

In conclusion, the striking difference in the choice of treatment between patients who made the decision concerning choice of treatment and those for whom physicians chose demonstrates the importance of patient preferences in decision making. Actively involving patients in the decision making process, demonstrates respect for their autonomy, an important aspect of patient-centered care.

\section{ACKNOWLEDGMENTS}

This research project has received funding from the UTS Business School Research Management Committee.

All named authors meet the International Committee of Medical Journal Editors (ICMJE) criteria for authorship for this manuscript, take responsibility for the integrity of the work as a whole, and have given final approval for the version to be published.

\section{Compliance with Ethical Standards}

Disclosures M Chin has received conference travel support from Boehringer Ingelheim, Lilly, Novartis, Bristol Myer Squibb and Pfizer. L Bloem, B Ly, M Haas and R De Abreu Lourenco have no conflicts of interest to declare. This article is based on previously treated patients and does not involve any new studies of human or animal subjects performed by any of the authors. Ethics approval for this study was obtained from the South Eastern Sydney Local Health District Human Research Ethics Committee (13/288) and ratified by the University of Technology Sydney Human Research Ethics Committee (2014000002).

Open Access This article is distributed under the terms of the Creative Commons Attribution-NonCommercial 4.0 International License (http://creativecommons.org/licenses/ by-nc/4.0/), which permits any noncommercial use, distribution, and reproduction in any medium, provided you give appropriate credit to the original author(s) and the source, provide a link to the Creative Commons license, and indicate if changes were made.

\section{REFERENCES}

1. Ferlay J, Soerjomataram I, Ervik M, Dikshit R, Eser S, Mathers et al. GLOBOCAN 2012 v1.2, Cancer incidence and mortality worldwide: IARC CancerBase No. 11 [Internet]. International Agency for Research on Cancer, Lyon, France. 2015. http://globocan.iarc.fr. Accessed July 23 2015.

2. Cartwright TH. Treatment decisions after diagnosis of metastatic colorectal cancer. Clinical Colorectal Cancer. 2012;11(3):155-66. doi:10.1016/j.clcc. 2011.11.001.

3. Price TJ, Segelov E, Burge M, Haller DG, Ackland SP, Tebbutt NC, et al. Current opinion on optimal treatment for colorectal cancer. Expert Rev Anticancer Ther. 2013;13(5):597-611. 
4. Twelves C, Scheithauer W, McKendrick J, Seitz J-F, Van Hazel G, Wong A, et al. Capecitabine versus 5-fluorouracil/folinic acid as adjuvant therapy for stage III colon cancer: final results from the X-ACT trial with analysis by age and preliminary evidence of a pharmacodynamic marker of efficacy. Ann Oncol. 2012;23(5):1190-7. doi:10.1093/annonc/ mdr366.

5. Twelves C, Boyer M, Findlay M, Cassidy J, Weitzel $\mathrm{C}$, Barker C, et al. Capecitabine (Xeloda) improves medical resource use compared with 5-fluorouracil plus leucovorin in a phase III trial conducted in patients with advanced colorectal carcinoma. Eur J Cancer. 2001;37(5):597-604.

6. Cassidy J, Douillard JY, Twelves C, McKendrick JJ, Scheithauer W, Bustova I, et al. Pharmacoeconomic analysis of adjuvant oral capecitabine vs intravenous 5-FU/LV in Dukes' C colon cancer: the X-ACT trial. Br J Cancer. 2006;94(8):1122-9.

7. Douillard JY, Tilleul P, Ychou M, Dufour P, Perrocheau G, Seitz JF, et al. Cost consequences of adjuvant capecitabine, Mayo Clinic and de Gramont regimens for stage III colon cancer in the French setting. Oncology. 2007;72(3-4):248-54.

8. Caponero R, de Albuquerque Ribeiro R, Santos E, Cirrincione A, Saggia M. Medical resource use and cost of different first-line treatments for metastatic colorectal cancer in Brazil. J Med Economics. 2008;11(2):311-25.

9. Di Costanzo F, Ravasio R, Sobrero A, Bertetto O, Vinante O, Luppi G, et al. Capecitabine versus bolus fluorouracil plus leucovorin (folinic acid) as adjuvant chemotherapy for patients with Dukes' C colon cancer: economic evaluation in an Italian NHS setting. Clin Drug Investig. 2008;28(10):645-55.

10. Tse VC, Ng WT, Lee V, Lee AWM, Chua DTT, Chau $\mathrm{J}$, et al. Cost-analysis of XELOX and FOLFOX4 for treatment of colorectal cancer to assist decision-making on reimbursement. BMC Cancer. 2011;11(288):1-8.

11. Pettersson K, Carlsson G, Holmberg C, Sporrong SK. Cost identification of Nordic FLIRI, Nordic FLOX, XELIRI and XELOX in first-line treatment of advanced colorectal cancer in Sweden-A clinical practice model approach. Acta Oncol. 2012;51(7):840-8.

12. van Gils CW, de Groot S, Tan SS, Redekop WK, Koopman M, Punt CJ, et al. Real-world resource use and costs of adjuvant treatment for stage III colon cancer. Eur J Cancer Care. 2015;24(3):321-32. doi:10.1111/ecc. 12154 .

13. Jansman FGA, Postma MJ, Hartskamp D, Willemse PHB, Brouwers JRBJ. Cost-benefit analysis of capecitabine versus 5-flourouracil/leucovorin in the treatment of colorectal cancer in the Netherlands. Clin Ther. 2004;26(4):579-89.

14. Twelves C, Gollins S, Grieve R, Samuel L. A randomised cross-over trial comparing patient preference for oral capecitabine and 5-fluorouracil/ leucovorin regimens in patients with advanced colorectal cancer. Ann Oncol. 2006;17(2):239-45.

15. Gornas M, Szczylik C. Oral treatment of metastatic breast cancer with capecitabine: what influences the decision-making process? Eur J Cancer Care. 2010;19(1):131-6.

16. Liu G, Franssen E, Fitch MI, Warner E. Patient preferences for oral versus intravenous palliative chemotherapy. J Clin Oncol. 1997;15(1):110-5.

17. Borner MM, Schoffski P, De Wit R, Caponigro F, Comella G, Sulkes A, et al. Patient preference and pharmacokinetics of oral modulated UFT versus intravenous fluorouracil and leucovorin: a randomised crossover trial in advanced colorectal cancer. Eur J Cancer. 2002;38(3):349-58.

18. Rocha Lima AP, Del Giglio A. Randomized crossover trial of intravenous 5-FU versus oral UFT both modulated by leucovorin: a one-centre experience. Eur J Cancer Care. 2005;14(2):151-4. doi:10.1111/j. 1365-2354.2005.00531.x.

19. Pfeiffer P, Mortensen JP, Bjerregaard B, Eckhoff L, Schonnemann K, Sandberg E, et al. Patient preference for oral or intravenous chemotherapy: a randomised cross-over trial comparing capecitabine and nordic fluorouracil/leucovorin in patients with colorectal cancer. Eur J Cancer. 2006;42(16):2738-43.

20. Rischin D, White MA, Matthews JP, Toner GC, Watty K, Sulkowski AJ, et al. A randomised crossover trial of chemotherapy in the home: patient preferences and cost analysis. Med J Aust. 2000;173(3):125-7.

21. Luthi F, Fucina N, Divorne N, Santos-Eggimann B, Currat-Zweifel C, Rollier P, et al. Home care-a safe and attractive alternative to inpatient administration of intensive chemotherapies. Support Care Cancer. 2012;20(3):575-81. doi:10. 1007/s00520-011-1125-9.

22. Borras JM, Sanchez-Hernandez A, Navarro $M$, Martinez M, Mendez E, Ponton JLL, et al. Compliance, satisfaction, and quality of life of patients with colorectal cancer receiving home chemotherapy or outpatient treatment: a randomised controlled trial. BMJ. 2001;322(7290):826. doi:10.1136/bmj.322.7290. 826. 
23. Schrag D, Cramer LD, Bach PB, Begg CB. Age and adjuvant chemotherapy use after surgery for stage III colon cancer. J Natl Cancer Inst. 2001;93(11):850-7. doi:10.1093/jnci/93.11.850.

24. Potosky AL, Harlan LC, Kaplan RS, Johnson KA, Lynch CF. Age, sex, and racial differences in the use of standard adjuvant therapy for colorectal cancer. J Clin Oncol. 2002;20(5):1192-202. doi:10.1200/ jco.20.5.1192.

25. Sundararajan V, Mitra N, Jacobson JS, Grann VR, Heitjan DF, Neugut AI. Survival associated with 5-fluorouracil-based adjuvant chemotherapy among elderly patients with node-positive colon cancer. Ann Intern Med. 2002;136(5):349-57. doi:10.7326/0003-4819-136-5-200203050-00007.

26. Ayanian JZ, Zaslavsky AM, Fuchs CS, Guadagnoli E, Creech CM, Cress RD, et al. Use of adjuvant chemotherapy and radiation therapy for colorectal cancer in a population-based cohort. J Clin Oncol. 2003;21(7):1293-300. doi:10.1200/jco.2003.06.178.

27. Jessup J, Stewart A, Greene FL, Minsky BD. Adjuvant chemotherapy for stage III colon cancer: implications of race/ethnicity, age, and differentiation. JAMA. 2005;294(21):2703-11. doi:10.1001/jama.294.21.2703.

28. Cronin DP, Harlan LC, Potosky AL, Clegg LX, Stevens JL, Mooney MM. Patterns of care for adjuvant therapy in a random population-based sample of patients diagnosed with colorectal cancer. Am J Gastroenterol. 2006;101(10):2308-18.

29. Kahn KL, Adams JL, Weeks JC, et al. Adjuvant chemotherapy use and adverse events among older patients with stage III colon cancer. JAMA. 2010;303(11):1037-45. doi:10.1001/jama.2010.272.

30. O'Grady MA, Slater E, Sigurdson ER, Meropol NJ, Weinstein A, Lusch CJ, et al. Assessing compliance with National Comprehensive Cancer Network guidelines for elderly patients with stage III colon cancer: the fox chase cancer center partners' initiative. Clinical Colorectal Cancer. 2011;10(2):113-6. doi:10.1016/j.clcc.2011.03.007.

31. Chagpar R, Xing Y, Chiang Y-J, Feig BW, Chang GJ, You YN, et al. Adherence to stage-specific treatment guidelines for patients with colon cancer. J Clin Oncol. 2012;30(9):972-9. doi:10.1200/jco.2011.39. 6937.

32. Deadman JM, Leinster SJ, Owens RG, Dewey ME, Slade PD. Taking responsibility for cancer treatment. Soc Sci Med. 2001;53(5):669-77. doi:10.1016/S0277-9536(00)00369-5.

33. Degner LF, Kristjanson LJ, Bowman D, et al. Information needs and decisional preferences in women with breast cancer. JAMA. 1997;277(18):1485-92. doi:10.1001/jama.1997. 03540420081039 .

34. Bruera E, Sweeney C, Calder K, Palmer L, Benisch-Tolley S. Patient preferences versus physician perceptions of treatment decisions in cancer care. J Clin Oncol. 2001;19(11):2883-5.

35. Damm K, Vogel A, Prenzler A. Preferences of colorectal cancer patients for treatment and decision-making: a systematic literature review. Eur J Cancer Care. 2014;23(6):762-72. doi:10. 1111/ecc.12207.

36. Satram-Hoang S, Lee L, Yu S, Guduru SR, Gunuganti $\mathrm{AR}$, Reyes C, et al. Comparative effectiveness of chemotherapy in elderly patients with metastatic colorectal cancer. J Gastrointest Cancer. 2013;44(1):79-88.

37. Healey E, Stillfried GE, Eckermann S, Dawber JP, Clingan PR, Ranson M. Comparative effectiveness of 5-fluorouracil with and without oxaliplatin in the treatment of colorectal cancer in clinical practice. Anticancer Res. 2013;33(3):1053-60. 